\title{
Bedouin Ethnobotany: Plant Concepts and Uses in a Desert Pastoral World
}

James P. Mandaville. 2010. The University of Arizona Press, Tucson. Pp. 352, 33b/w photos, 2 maps, 5 tables. $\$ 55.00$ (hardcover + CD). ISBN 978-0-8165-2900-1.

\section{Reviewed by Nemer E. Narchi}

Reviewer address: Departamento de Relaciones Sociales, Universidad Autónoma Metropolitana-Unidad Xochimilco, Calzada del Hueso 1100, Mexico City, Mexico 04960. nenarchi@gmail.com

Dry heat, tremendous temperature fluctuations, and the access to and availability of water, are some of the common challenges that humans face in arid and desert ecosystems. Yet, human societies that have lived in these ecosystems lessened these adversities through diverse and ingenious cultural strategies. Regardless of how impressive these strategies are, they would be ineffective without a vast reservoir of knowledge on the utilization of plants and animals.

Amongst the vast number of peoples that have adapted to arid and desert environments, it is my opinion that few cultures are as iconic to the collective imaginaries as Middle Eastern Bedouins. However, the conjuring of this rich and exotic image as a contemporary phenomenon lacks verisimilitude. Presently, a majority of the Bedouin tribes in the Middle East share the common problems of a changing world: forced settlement, displacement, encroachment, and range shrinkage.

With the former in mind, it is easy to appreciate the value of the book James P. Mandaville has prepared with data collected over 15 years starting in 1960 when Bedouin lifestyle started shifting from semi-nomadic pastoralism to urbanism.

The book is divided into 7 chapters: 1) the study area, with an explanation of the features of land climate and vegetation; 2) the people, with a description on the livelihoods of 9 different Bedouin tribes; 3) a section on the functional aspects of plant knowledge; 4) a list of plants and their uses; 5) plants as concepts and names; 6) generics and subgenerics, with a descriptive section on folk categories; and 7) plant lore in space and time, with a section discussing the temporal and geographic stretch of Bedouin plant lore.
After a concise introduction describing the scope of the research, previous work, and research chronology, the authors present a description of research consultants, features of Najdī Arabic dialect, and working procedures. The reader is greeted with an indepth description of the area of study, starting with geology and topography. Throughout his orographic sketch, Mandaville manages to sprinkle in facts on cultural change among Bedouins, a style all ethnobiologists might benefit from. I appreciated encountering narrations on Bedouin use of off-road vehicles and deep water oil wells, especially in the section devoted to geology and topography. These ethnographic treats help incorporate the essence of today's Bedouins into the author's description of the local landscape and thereby demonstrate its relevance to them.

In chapter 2, the author describes the people briefly but comprehensively, touching on various aspects that include political organization, land property regimes, gender-based administration of dwellings, the household economy, and market relationships with towns and cities. One thing I find problematic is that the author explains government policies towards Bedouins only superficially and in apolitical terms. For example, Mandaville organizes all reasons behind forced settlement under the term "modernization" without further discussion of the implications, motivations, and results of these policies for "modernizing" Bedouins.

I found chapter 3, a section on stars, land, and plants, to be one of the best parts of the book, as it situates the reader inside a nomadic expedition, whose success depends on the members' abilities to know, recognize, and anticipate the sprouting and blooming of desert vegetation throughout their territories. This 
is a compelling effort that highlights the most important components of ethnobiological knowledge - its practical and operational aspects.

Chapter 4 presents a large compilation of culturally important plants. The list includes those used as livestock feed, fuel, food, and medicine. Among these descriptions, I found the accounts of plants used in children's play to be the most interesting. What could be called the cultural domain of ludic plants is not very large, but is markedly diverse as it encompasses plant collections, sources of pigments for young girls, and, the one I liked the most because it reflects the incisive nature of play, Farsetta aegyptia Turra Brassicaceae, which is used as "itching powder."

The descriptions of plants are complemented by a supplementary CD with outstanding color images of many of the taxa presented in the book.

I found Mandaville's most remarkable contribution to be his discussion in chapter 5 of plants as concepts and names. His conclusions align with the biological and nomenclatural features that would be expected for hunters, foragers, and pastoralists based on Brent Berlin's models. That is, Bedouin generics are overwhelmingly monotypic with the exception of taxa with particularly important cultural salience.

In chapter 6, Mandaville contributes to the continuing debate about intellectualist versus utilitarian notions of the nature of ethnotaxonomies by supporting Berlin's intellectualist approach with an interesting utilitarian twist. I wish that these arguments had been available when ethnoclassification was the main focus of ethnobiology. However, these data remain relevant to this debate.

James P. Mandaville has integrated all of his experience and narrative brilliance in a volume that is much more than just another ethnobotanical inventory. It is a well balanced monograph touching on many aspects of a culture that is transforming with dramatic speed and in many directions, as noted in chapter 7. Ethnobiologists interested in cultural change among Arabic Bedouins, as well as ethnologists willing to revisit the wonderful subject of ethnotaxonomies, should consider keeping a copy of Bedouin Ethnobotany nearby.

The book makes a valuable contribution because it provides a written record of many ethnobotanical practices that have no present equivalent. However, the book's most important achievement is its blending of the chapter topics into a conceptual whole which communicates Bedouin relations with the vegetation of a territory to which they are deeply attached emotionally and outstandingly adapted to culturally.

Finally, as a researcher with a deep interest in arid livelihoods but only tangential interests in Arabic culture, I found the book to be amusing, the narrative to be deeply vivid, and the pictures to be excellent. It is worth reading just for the pleasure of doing so. 